\title{
Algunos aspectos de la eVOLUCiÓN
}

\author{
DE LA VEGETACIÓN DE MÉXICO
}

\author{
Francisco González-Medrano
}

\begin{abstract}
Departamento de Botánica, Instituto de Biología, Universidad Nacional Autónoma de México.
\end{abstract} Ciudad Universitaria, 04510, México, D.F., México.

\begin{abstract}
Resumen. Diferentes factores han influido en la conformación de la vegetación de México: su posición geográfica, la orogenia y el vulcanismo, las emersiones e inmersiones, las fluctuaciones climáticas del terciario y las glaciaciones, así como las migraciones que en diferentes tiempos y direcciones se han presentado. Otro aspecto que también contribuyó en gran medida a diversificar la flora y la vegetación del país ha sido el desarrollo del elemento endémico en la flora y aún en la vegetación. Este elemento es altamente significativo en los matorrales xerófilos y en los bosques templados. Todo ello hace muy complejo el análisis fitogeográfico de la flora, lo cual también se complica por la coexistencia, en algunas comunidades, de plantas de diferentes orígenes, edades y con historias evolutivas diferentes.

Palabras clave: evolución, México, migración, origen, vegetación.

Abstract. Various factors háve influenced the characteristics of vegetation over Mexico such as: geographical position, orography, volcanism, emersions and inmersions, climatic fluctuations during the Tertiary, glaciations as well as various migrations that have taken place at various times in varius directions. Another aspect that has contributed to the diversity in flora and vegetation in Mexico is the development of an endemic element in flora and even in vegetation. This is important specially to xerophitic and temperate forest. All of this results in a complex phytogeographic analysis of flora due to the co-existence, in some communities, of plants with various origins, ages and evolutive histories.
\end{abstract}

Key words: evolution, Mexico, migration, origin, vegetation.

a historia y la evolución de la vegetación de México puede comprenderse mejor si su desarrollo se analiza bajo la perspectiva de los siguientes factores:

- La posición que Norteamérica y en especial la parte que corresponde al territorio mexicano, han tenido a lo largo del tiempo geológico con una gran parte de su superficie en posición intertropical y en medio de dos océanos.

- Las fluctuaciones climáticas durante gran parte del Terciario y del Cuaternario, sobre todo las últimas glaciaciones.

- Las emersiones e inmersiones de gran parte del territorio mexicano.

- La orogenia y el vulcanismo con la subsecuente diversidad del substrato geológico y consecuentemente del suelo desarrollado.

- Las migraciones de la biota, especialmente la flora fanerogámica.

Aunque es evidente que las migraciones y el establecimiento de las especies se ha hecho en forma individualizada, algunos patrones de distribución de algunas especies son sin embargo, altamente coincidentes, lo cual permite un grado de asociación ecológica (convergencia adaptativa) razonablemente homogéneo, facilitando junto con las formas de vida y la composición florística, su diferenciación en comunidades vegetales; además permitiendo esto el análisis de su historia y evolución de éstas.

- El hecho de que gran parte del territorio mexicano esté considerado como un centro de origen y diversificación de la flora, especialmente las áreas montañosas y la porción norte.

- Un factor importante, que limita en gran medida el conocimiento de la evolución y el desarrollo de la vegetación en México, es la dificultad de contar con información paleobotánica completa, pues tenemos que auxiliarnos con estudios escasos, a veces inconexos en tiempo y espacio o con información derivada de microfósiles, la que a menudo resulta en cierta medida contradictoria al compararla con macrofósiles de la misma región. 
Posibles orígenes y evolución de algunas comunidades vegetales de México

Actualmente, en la conformación de la vegetación del país, podemos diferenciar dos grandes tipos de comunidades vegetales: unas, influidas de una forma más directa por el tipo de suelo o de substrato geológico (comunidades edáficamente controladas) y otras cuya expresión está influida de una forma más directa por el factor climático. En lo sucesivo, nos referiremos básicamente a éstas. Así, podemos diferenciar dos tipos de comunidades vegetales: las tropicales, tanto del trópico seco como del húmedo, en las que en sus áreas de distribución no se presentan heladas, y las templadas, en las que frecuentemente o eventualmente se presentan heladas, incluyendo las de zonas áridas.

\section{La vegetación tropical}

Este tipo de vegetación está representado en nuestro país por los bosques tropicales o selvas, las altas perennifolias, las medianas y las bajas caducifolias y sus variantes.

En la conformación de la flora característica de estas formaciones podemos diferenciar linajes muy antiguos provenientes de Norteamérica y linajes más recientes de edad neogénica (Mioceno a Plioceno), los cuales presumiblemente arribaron desde Sudamérica. Al respecto cabe destacar los trabajos de Graham (1977), del Mioceno Superior (14-15 m.a.p.) de Veracruz de la Formación Paraje Solo, en los que encuentra que de las siete especies dominantes de la selva alta perennifolia actual de Veracruz, solo una, (Terminalia) ha sido tentativamente identificada en la microflora, y que la presencia de Picea en las muestras de esta formación, claramente evidencia un clima más frío en el sureste de México en tiempos Mio-Pliocénicos. Aunado a lo anterior, la presencia de géneros hoy en día más bien propios del bosque mesófilo de montaña, esparcidos entre las selvas altas perennifolias, se ha interpretado como reliquias de períodos anteriores más fríos, por ejemplo: Myrica, Podocarpus, Pinus, Quercus, etc. Aunque elementos de la selva alta perennifolia estaban presentes en Veracruz en el Mioceno Superior (Astrocaryum, Matayba, Hiraea, Eugenia, Terminalia) aparentemente no conformaban una comunidad de selva alta, equivalente a la que actualmente se presenta en ese estado. Graham (1977) deja entrever la posibilidad de que la selva alta de Veracruz, cuando menos en su forma actual, pueda ser de origen post-glacial.

Sin embargo, para otras áreas de selva alta perennifolia, Chiapas por ejemplo, se han identificado elementos muy antiguos de claro origen meridional, especialmente Sudamérica, los cuales pudieron haber arribado a México a través de conexiones originalmente de África-Eurasia y luego por el estrecho de Bering y/o el Atlántico Norte, por ejemplo: Bursera, Prosopis y quizás Roupala. O bien conexiones sudamericanas más recientes, cuando la comunicación terrestre entre Norte y Sudamérica fue posible, hace 5.7 millones de años, por ejemplo: Bernoullia, Faramea, Pelliciera, Cecropia, Vatairea, Virola, Vochysia, etcétera.

Durante el Terciario Medio, otros elementos pudieron haber migrado a través del arco antillano, como: Casearia, Merremia, Rauvolfia, Zanthoxylum, o bien haberse originado en la región Caribe y posteriormente migrado a México, como: Jacquinia, Machaonia, Exostema, Harpalyce, Pisonia, Sabal, Zamia, Malpighia, etcétera.

Algunas migraciones Sudamericanas a México, parecen ser más recientes, como las de Amicia, Hesperozygis, Larrea y otras.

El elemento endémico en la flora del trópico húmedo de México, sin ser especialmente significativo, está presente. Para el área de la Lacandonia, Wendt (1993) señala: Lacandonia, Blepharidium guatemalense, Luehea seemannii, Orthion subsessile, Sebastiana tuerckheimiana, y Pourouma guianense. Otro grupo de endemismos casi restringidos a las zonas más húmedas de Uxpanapa (algunos alcanzan Tabasco), comprenden: Chiangiodendron mexicanum, Elaeagia uxpanapensis, Recchia simplicifolia, Robinsonella samaricarpa, o algunas que extienden su área de distribución hasta la región de los Tuxtlas, como: Erythrina tuxtlana, Gaussia gomez-pompae, Licaria velutina, Ocotea uxpanapana, Robinsonella brevituba, Rondeletia galeottii y otras.

Los trabajos de Graham $(1977,1993)$, Wendt (1993), Miranda y Sharp (1950), Toledo (1976), y otros, han permitido formarse una idea acerca del origen y la evolución de la vegetación tropical de México. Respecto a la composición de la flora, Wendt (1993), basado en un análisis completo de las especies de árboles que conforman el estrato superior de los bosques lluviosos de México, ha concluido que en la composición de la vegetación tropical de México (cuando menos del dosel arbóreo), existe un abigarrado conjunto de diferentes orígenes y de diferentes edades. Las fluctuaciones climáticas y especialmente la estacionalidad de las precipitaciones han influido en la presencia, la distribución y aun la extinción de los taxa.

La diversidad geológica y topográfica a través del Cenozoico, combinada con las fluctuaciones climáticas y la localización del país entre dos océanos, ha permitido que diferentes tipos de vegetación puedan coexistir en proximidad.

La conexión de México con el resto de Norteamé- 
rica, fue establecida desde tiempos tan antiguos como Jurásico y Cretácico Inferior, y en especial con la porción occidental de Norteamérica, cuando menos desde el Cretácico Superior.

Por Eurasia, a través de las vías terrestres nor-atlánticas y desde Sudamérica vía las proto-antillas o a través del arco antillano, se dieron inmigraciones eocénicas o anteriores de taxa provenientes de Eurasia y de África, durante períodos de amplia extensión mundial de climas megatérmicos.

También hubo migraciones miocénicas y posteriores, (especialmente del Plioceno al presente) de elementos sudamericanos megatérmicos hacia Mesoamérica, a través de un puente terrestre panameño.

Se dieron ciclos climáticos neógenos y pleistocénicos que llevaron a la extinción local y a veces a reinvasiones subsecuentes en todo o en parte del sureste de México y Mesoamérica.

Los océanos por su naturaleza amortiguadora sobre el clima, a través de gran parte de todo el Cenozoico, favorecieron la presencia de los "taxa" más sensibles durante los períodos de clima adverso y finalmente la presencia de grandes extensiones de terrenos con una topografía cárstica en la porción norte de Mesoamérica.

Estos factores, más el potencial genético evolutivo de las especies, han permitido tener la riqueza de la flora del trópico de México.

En el estrato arbóreo de la vegetación del trópico de México, además del elemento endémico, pueden reconocerse los siguientes elementos florísticos:

\section{De antiguo arribo}

a) Antiguos elementos laurásicos descendientes de linajes que inmigraron durante el Eoceno antes y que sobrevivieron en Mesoamérica o invadieron Sudamérica y posteriormente reinvadieron Mesoamérica.

Esto último incluye linajes tanto de familias laurásicas como gondwánicas, probablemente siguiendo una ruta África-Eurasia-Norteamérica.

b) Elementos que arribaron desde Sudamérica, descendientes de linajes que inmigraron a través de una vía protoantillana o antillana, durante o probablemente antes del Eoceno.

\section{Arribos recientes desde Sudamérica.}

a) Arribos de edad neógena que sobrevivieron a través de los ciclos climáticos pleistocénicos en al menos la parte sur de Mesoamérica.

b) Arribos más recientes, como los que se dieron durante el Holoceno, aunque no necesariamente a principios de este período.

\section{Bosques templados}

Se incluyen aquí aquellas comunidades vegetales dominadas por árboles, distribuidas en áreas donde se presentan heladas en forma eventual o periódica y generalmente distribuidas en las zonas montañosas. Quedan aquí comprendidos los bosques de encino, los de pino-encino, de oyamel o abeto y los bosques mesófilos de montaña, así como matorrales esclerófilos o chaparrales.

La historia de la biota templada para el occidente de Estados Unidos de Norteamérica, está razonablemente bien documentada (Graham, 1964, Raven y Axelrod, 1974); en menor proporción se conoce la del este y sureste. De estos estudios, se han puesto de manifiesto las estrechas relaciones con los bosques templados de México. Gran parte de la porción oriental de Estados Unidos y de México estuvo cubierta por mares terciarios, los cuales al retirarse favorecieron la creación de áreas en las que se desarrollaron floras muy peculiares, entre ellas la Flora Wilcox del Eoceno, la cual ocupó gran parte de la cuenca media y baja del Río Misisipi. Los megafósiles (especialmente hojas), reflejan en el área costera una vegetación tropical con géneros como: Anemia, Lygodium, Zamia, Canna, Ficus, Manihot, Cedrela, Banisteria, Sterculia, Artocarpus, Coccoloba, etcétera. Sin embargo, analizando la composición florística de los microfósiles, se encontró una mayor representación de especies templadas que crecían más tierra adentro y que probablemente eran más significativas a nivel regional, destacando géneros como: Tilia, Alnus, Ulmus, Ostrya, Carpinus, Carya, Celtis, Fagus, Juglans, Liriodendron, Magnolia, Osmanthus, Liquidambar, Myrica, Nyssa, Quercus, Pinus, Cercis, y otros. Con el progresivo enfriamiento del clima, parte de esta flora comenzó a migrar hacia el sur, estimándose que alcanzó México durante el Oligoceno. La orogenia Hidalgoana del Eoceno, (De Cserna, 1974, Guzmán y De Cserna, 1963) que culminó con el levantamiento de la Sierra Madre Oriental de México, debió favorecer, ya avanzado el Terciario, la migración de esta flora norteña templada.

En cuanto a los orígenes, algunos elementos de esta flora se remontan al Cretácico Inferior de Maryland. Entre otros pudieron reconocerse géneros como: Populus, Sassafras, Diospyros, Liriodendron, Magnolia, Myrica y Salix. Del Cretácico Superior de Long Island, Steeves (1959), Hollick (1906) y Berry (1911), identificaron megafósiles de: Acer, Rhus, Cordia, Viburnum, Calastrus, Cormus, Diospyros, Quercus, Ilex, Juglans, Magnolia, Platanus, Rhamnus, etc. La distribución en Eurasia de muchos de estos géneros, supone una mayor continuidad de una flora laurásica templada en el hemisferio norte. 
A fines del Oligoceno y principios del Mioceno, se nota el florecimiento de una flora templada norteña, distribuida en latitudes medianas y altas de Asia Boreal, Norte América y Europa, de donde se extendió al sur, alcanzando nuestro país, para contribuir a la conformación de una de las comunidades más ricas florísticamente: el bosque mesófilo de montaña o bosque de niebla.

\section{Bosque mesófilo de montaña}

Bajo esta denominación, Miranda (1948) se refirió a una comunidad vegetal, que se desarrolla en la cuenca del Río Balsas en la vertiente pacífica de México, en el mismo piso altitudinal de los bosques de encino, pero en sitios en donde las condiciones de humedad son más favorables como barrancas o cañadas y en donde la presencia de la niebla obra como un factor ecológico de compensación. El mismo autor, junto con Sharp (1950), se refirió a una comunidad análoga, el bosque caducifolio o bosque de niebla en la vertiente atlántica. Sus relaciones fitogeográficas parecen ser claras con los bosques hoy presentes en las porciones oriental y suroriental de Estados Unidos y con algunas porciones del sur y sureste de Asia. (Dressler, 1954, Martín y Harrell, 1957; Sharp, 1966).

Sharp (1951) analizó la relación de la Flora Wilcox del Eoceno del sureste de Estados Unidos con algunas floras modernas, y encontró que una gran proporción de los géneros (93 de los 137) reconocidos como de la Flora Wilcox, persisten aun en la parte oriental de México o sea el $69 \%$, principalmente en las áreas de distribución del bosque mesófilo y áreas adyacentes.

Tal relación atestiguada por la presencia de géneros presentes en los bosques mesófilos de México, como: Aralia, Aristolochia, Bumelia, Carya, Diospyros, Engelhardtia, Eugenia, Fagus, Juglans, Fraxinus, Ilex, Liquidambar, Magnolia, Myrica, Nyssa, Osmanthus, Platanus, Prunus, Ptelea, Rhamnus, Sapindus, Smilax, Sophora, Staphylea, Ziziphus, etc., muchos de los cuales extienden su área de distribución a la porción sureste y oriental de Estados Unidos, y aún algunos al centro y oriente de China.

$\mathrm{Al}$ respecto, la presencia en México de un bosque mesófilo con algunos de estos elementos en afloramientos del Mioceno Inferior del noreste de Chiapas y de la Formación Paraje Solo, del Mioceno Superior de Veracruz, refleja que parte de los elementos que hoy conforman los bosques mesófilos se encontraban ya desde mediados y fines del Terciario en México. Algunos géneros hoy presentes en los bosques mesófilos de México se consideran de origen asiático y de climas templados como: Cleyera, Engelhardtia, Liquidam- bar, Microtropis, Mitrastemon, Osmanthus y Ternstroemia. Algunos grupos subtropicales antiguos también de ascendencia asiática serían: Annona, Cedrela, Celastrus, Dendropanax, Meliosma, Ocotea, Persea, Sassafras, Saurauia, Stemmadenia, Ternstroemia, Symplocos, etcétera.

\section{Vegetación esclerófila: chaparral}

Otra comunidad vegetal templada, especialmente interesante es el chaparral o matorral esclerófilo. Se considera que formó parte de la llamada Flora Madroterciaria del Eoceno y Oligoceno del suroeste de Estados Unidos (Axelrod 1958, 1979).

Actualmente se distribuye en nuestro país desde el norte de Baja California Norte, parte de Chihuahua, Coahuila, Nuevo León, Tamaulipas, San Luis Potosí, Hidalgo, Puebla y Oaxaca, alcanzando su límite sur en Chiapas en el área de Comitán. Algunos de los géneros mencionados de esta geoflora madroterciaria y que persisten en los chaparrales de México son: Amelanchier, Arbutus, Arctostaphylos, Bursera, Castela, Ceanothus, Celtis, Cercocarpus, Condalia, Eysenhardtia, Forestiera, Fraxinus, Garrya, Juniperus, Leucaena, Quercus, Pinus, Randia, Salix, Vauquelinia, etcétera.

\section{Bosques mixtos de pino-encino}

Según Florin (1963), las Pinaceae y el género Pinus, se originaron en el hemisferio norte durante el período Jurásico de la Era Mesozoica y aunque es difícil ubicar el lugar de origen, Laurasia parece ser el más factible. Se considera que los ancestrós de los pinos mexicanos han existido en Norteamérica desde el Cretácico Inferior, de donde conos similares a los de P. devoniana var. cornuta, han sido reportados por Chaney (1954 en Styles, 1993). Se piensa que no formaron extensos bosques, sino que más bien estaban esparcidos. Se cree que aicanzaron el territorio mexicano desde Estados Unidos, aparentemente cerca de la mitad del Terciario, y que los últimos lo hicieron a mediados del Cenozoico (Miller 1977). Por su parte, autores como Mirov (1967), sugieren que los primeros llegaron a México a través de la Sierra Madre Occidental, desde la cordillera norteamericana, durante fines del Cretácico y a principios del Terciario. Martin y Harrel (1957), al analizar parte de esta historia de la biota templada de México y sureste de Estados Unidos, proponen que hubo una migración posterior de pinos a mediados del Terciario desde las tierras elevadas de los Apalaches de la porción oriental de los Estados Unidos, rodeando el Golfo de México y a lo largo de la Sierra Madre Oriental, conjuntamente con otros géneros de angiospermas como: Quercus, Alnus, Carpinus, Ostrya, Magnolia y Liquidambar. 
Styles (1993) sugiere una idea interesante acerca del carácter pionero de los pinos. Menciona que posterior al proceso de vulcanismo que se presentó en gran parte de México, las áreas volcánicas representaron un hábitat favorable para la expansión del género. Este punto de vista es altamente coincidente con otros autores, como Spuirr (1964 en Komarek, 1983), que menciona la influencia del fuego como favorecedor de la dominancia de Pinus y Quercus en muchos de los bosques de las zonas templadas. Textualmente Spurr menciona: "around the world, the dominance of pine and oak forest of virtually all species and in virtually all regions is due predominantly to fire".

Respecto al otro acompañante común de los pinos, es decir el género Quercus, megafósiles (las hojas por ejemplo) no se conocen de México asignables al género. Sin embargo, son frecuentes en localidades Terciarias del occidente de Estados Unidos, aunque se conocen bellotas fósiles del Eoceno de Oregon (Manchester, 1983). Éstas no pueden ser asignadas inequívocamente al género Quercus en este tiempo. Compresiones de hojas fósiles atribuibles a Quercus, que claramente semejan especies modernas de encinos rojos, ahora presentes en México como Quercus sartorii, o Quercus acutifolia, se conocen del Oligoceno de Texas. Nixon (1993), basado en los trabajos existentes y otros en proceso, hace una razonable estimación de las especies de.Quercus para el Hemisferio Norte y considera unas 200 a 250 especies, de las cuales, unas 135 especies se presentan total o parcialmente en México. Con estudios posteriores, este número podría incrementarse a unas 150 . De esas 135 especies hasta ahora conocidas, unas 86 se consideran endémicas.

Existe un cierto paralelismo de las especies de Quercus con las del género Pinus, pues ambos tienen un cierto grado de adaptación a quemas periódicas, tales como el desarrollo de gruesas cortezas aislantes del fuego, la posesión de yemas adventicias, algunas en las raíces. En el caso de los encinos su regeneración se favorece después de incendios severos. Asimismo, pinos y encinos comparten el carácter pionero en ambientes que han sido sometidos a incendios.

\section{Vegetación xerófila incluyendo pastizales}

Diferentes autores, (Axelrod, 1958, 1979; Wells, 1977) han sugerido un origen reciente de las comunidades vegetales de zonas áridas. Para el desierto sonorense, Axelrod (1979) sugiere que debieron haberse originado a partir de una flora preadaptada a la condición de aridez que se desarrolló desde mediados y fines del Terciario y que alcanzó su climax en tiempos post-pleistocénicos como respuesta al efecto de sombra orográfica que trajo consigo el levantamiento de la Sierra Nevada. Algunos autores consideran que el enfriamiento de la corriente marina fría en California, pudo haber comenzado hace menos de 2,800 años, lo cual habría aumentado la condición de aridez a nivel regional.

La orogenia Hidalgoana (Eoceno), De Cserna (1974) y Guzmán y De Cserna (1963) y más recientemente el vulcanismo del Neogeno que afectó la parte media de la República Mexicana, favorecieron la formación de regiones áridas y semiáridas a sotavento de los macizos montañosos formados.

Rzedowski $(1962,1975)$ considera que la diversidad y en algunos casos la singularidad de las formas de vida, la gran proporción de géneros y especies endémicas en las zonas áridas de México, así como una alta proporción de grupos monofiléticos como: Crossomataceae, Koeberliniaceae, Simmondsiaceae, Nolinaceae, etc., parecen atestiguar una antigüedad mayor para las zonas áridas de México, sobre todo para aquellas del centro y norte. A nivel genérico la presencia de algunos endemismos como: Aconthothamnus, Bonetiella, Dicranocarpus, Dyscritothamnus, Gouldochloa, Mirandea, Mortonia, Neoeplingia, Orthosphenia, Oaxacania, Pringleochloa, Rzedoruskia, Sericodes, Setchellanthus, Viscainoa y otros, parecen reforzar, junto con el alto porcentaje de endemismos a nivel específico, la aseveración anterior.

Medellín (1982), sugiere que la conformación del desierto chihuahuense debió haberse efectuado como una consecuencia de la orogenia Laramide de fines del Mesozoico y de principios del Cenozoico, que trajo consigo la conformación de la Sierra Madre Oriental y del Altiplano Mexicano, creando condiciones de aridez a sotavento del macizo montañoso levantado.

Dicho autor considera que una primera colonización del actual desierto chihuahuense pudo haber comenzado con elementos florísticos preadaptados a un cierto grado de aridez. Estima que esta primera colonización se pudo haber llevado a cabo con especies paleotropicales pertenecientes a géneros tales como: Acacia, Aristida, Artemisia, Atriplex, Cassia, Dodonaea, Ephedra, Frankenia, Jatropha, Lycium, Menodora, Mimosa, Notholaena,Peganum, Solanum, Suaeda, etc. los cuales actualmente están representados por una o varias especies en todos los tipos de vegetación.

Junto con estas plantas, pudieron haberse desarrollado los paleoendemismos compartidos con las zonas áridas de Norte América entre ellos: Fouquieria y Mortonia, con varias especies, y géneros monotípicos como: Adolphia, Chilopsis, Holacantha, Lindleyella, o bien Orthosphenia. 
Simultáneamente con esta formación de paleoendemismos el desarrollo del pastizal desértico debe haberse iniciado como parte de una segunda etapa, no como un endemismo a nivel específico o genérico, sino como un endemismo a nivel de toda la vegetación. Este endemismo está claramente representado por el pastizal gipsófilo que aparentemente es exclusivo del desierto chihuahuense, (Rzedowski 1975). En estos pastizales existen especies endémicas de los géneros Bouteloua, Muhlenbergia, y algunas del género Sporobolus; además de especies de Dalea, Flaveria, Frankenia, Dicranocarpus, Nerysirenia, y otras.

Una tercera etapa pudo estar marcada por la primera comunicación con la porción sur del continente americano durante el Terciario, lo que permitió una primera contribución de elementos neotropicales adaptados a la aridez, por ejemplo algunas especies de géneros como Castela, Condalia, Flourensia, Franseria, Guterriezia, Larrea, Prosopis, Sanvitalia, y otras.

Una cuarta etapa hacia la completa colonización del desierto chihuahuense pudo ser la ocupación de los cerros de origen sedimentario marino o constituidos por calizas, por elementos de origen neotropical, pero no muy bien adaptados en un principio a la aridez, aunque con ciertas preadaptaciones a una falta relativa de agua. Entre estos elementos había especies de Agave, Echeveria, Hechtia y Yucca.

Un quinto paso pudo darse por la colonización de las efusiones de lava ya consolidadas, por elementos mesófilos que poco a poco se fueron adaptando a la condición de sequía. Tales elementos también de origen neotropical, dieron origen a una gran cantidad de neoendemismos entre ellos algunos representantes de los géneros Agave, Bursera, Hechtia, Opuntia y otros géneros de cactáceas, así como otros representantes de los matorrales crasicaules.

Una sexta etapa pudo haber sido una nueva contribución sudamericana de la flora montañosa, especialmente de compuestas como Baccharis, Brickellia y Zinnia, que pudieron haber dado los toques finales a todos los tipos de vegetación locales.

Medellín (1982), al considerar la reseña histórica del desarrollo de la vegetación del desierto chihuahuense, la presenta como una serie de pasos consecutivos, pero menciona que posiblemente numerosos fenómenos ocurrieron simultáneamente.

Respecto a los pastizales, aunque se conocen fósiles de gramíneas del Cretácico Superior de Coahuila, que posteriormente fueron identificados como pertenecientes al género Chusquea, estos registros fósiles son aislados, (Rueda-Gaxiola, 1967). Parece ser que las primeras comunidades de pastizal, es decir con predominio de gramíneas o formas graminoides, pudieron haberse comenzado a diferenciar durante el Eoceno Superior en el centro norte de México y posteriormente haber invadido el sur y sudoeste de Estados Unidos. Axelrod (1979) considera que los pastizales de esta región debieron haberse desarrollado como tales, en tiempos más recientes. El levantamiento de la Sierra Nevada en Estados Unidos, durante parte del Plioceno y Pleistoceno y más recientemente el enfriamiento progresivo de la corriente marina fría de California, contribuyeron a aumentar las condiciones de aridez del suroeste de Estados Unidos y del norte de México.

Las fluctuaciones de épocas frías y húmedas, secas y cálidas durante el Pleistoceno, además de que contribuyeron a diversificar la flora y la vegetación, empujaron a los pastizales desde el suroeste hasta el centro oeste de Estados Unidos, en donde ya había representantes de estos pastizales aparentemente emigrados desde el norte de México.

Se considera que el territorio nacional alberga más de mil especies de gramíneas tanto introducidas como nativas, incluyendo las endémicas, repartidas en unos 170 géneros; del millar de especies, se estima que un $20 \%$ sean endémicas a México, ocupando aproximadamente el $10 \%$ del territorio nacional.

Desde el punto de vista ecológico, los pastizales naturales pueden agruparse en: pastizales climáticos, en donde el clima es el factor que de una manera más directa influye en su desarrollo y distribución, y aquellos pastizales en los cuales el suelo y/o el substrato geológico son el factor determinante para su expresión.

Algunos pastizales climáticos se desarrollan en las partes elevadas de las montañas, ya sea formando parte del sotobosque de los pinares u oyametales, o por encima del límite arbolado de la vegetación, constituyendo los pastizales amacollados de altura. Otro grupo de pastizales climáticos lo constituyen aquellos que se desarrollan en zonas semiáridas, o bien, los que ocupan áreas ecotonales entre las zonas áridas y las zonas templadas.

Dentro del grupo de pastizales edáficamente controlados, destacan los pastizales halófilos, comunes en cuencas endorreicas salinizadas o bolsones y los que ocupan algunas áreas costeras marinas.

En el centro norte de México, en los afloramientos de yeso del desierto chihuahuense, se desarrolla una comunidad de pastizal que según Rzedowski (1975), es un endemismo a nivel comunidad vegetal. Para este pastizal gipsófilo y la flora asociada, Powell y Turner (1977), postulan una historia evolutiva muy antigua, atestiguada por los endemismos a nivel genérico, lo caracterizan géneros como Dicranocarpus, Flaveria, Nerisyrenia, Sartwellia y otros. 


\section{Conclusiones}

El tratar de integrar los aspectos sobre la historia y la evolución de la vegetación de México es difícil, porque la información disponible está aislada, incompleta e inconexa en tiempo y espacio. Sin embargo, pueden hacerse algunas generalizaciones.

Además del elemento endémico, que para algunas comunidades es importantísimo, en la conformación de las comunidades vegetales modernas de México, se han conjugado elementos de diferentes orígenes y edades. La proporción de elementos neotropicales es considerablemente mayor; le seguiría el elemento endémico y en menor proporción el boreal (Rzedowski, 1962, 1991).

El elemento endémico se manifiesta no sólo a nivel de taxa (familia, género y especie), sino a nivel de comunidad vegetal, tal es el caso de los pastizales gipsófilos (Rzedowski, 1975).

Para la vegetación xerófila de México, las peculiaridades de su evolución, las formas de vida y la gran proporción de taxa endémicos (algunos a nivel genérico) sugieren una gran antigüedad y un desarrollo bajo condiciones de aislamiento.

La migración de la flora se ha presentado en diferentes tiempos, y direcciones, tanto norte como sur, como sur-norte y por diferentes rutas migratorias.

Parte del territorio mexicano aparentemente ha sido un centro importante de origen $y / o$ diversificación de la flora, especialmente las áreas montañosas y el norte de México.

En algunas comunidades vegetales de zonas áridas coexisten como codominantes taxa de edades, orígenes e historias evolutivas diferentes.

Todo lo anterior ha contribuido a la dificultad para entender los orígenes y la evolución de la flora y la vegetación de México.

\section{Agradecimientos}

Los Dres. S. Cevallos Ferriz del Instituto de Geología, y F. Chiang Cabrera del Instituto de Biología de la UNAM, leyeron críticamente el escrito original; les agradezco sus observaciones y sugerencias. La Bióloga G. Gabriela Hernández Mejía, transcribió paciente y entusiastamente el manuscrito. Gracias Gabriela.

\section{Literatura citada}

Axelrod D. 1958. Evolution of the Madro-Tertiary Geoflora Botanic Review 24:433-509.

Axelrod D. 1979. Age and Origin of the Sonoran Desert Vegetation. Occasional papers of the California Academy of Sciences 132:74.
Berry E.W. 1911. Contributions to the Mesozoic flora of the Atlantic coastal plain. Bulletin Torrey Botanic Club, 38:399-424.

Chaney R.W. 1954. A new pine from the Cretaceous of Minnesota and its paleoecological significance. Ecology 35:145-151.

De Cserna Z. 1974. La evolución geológica del panorama fisiográfico actual de México. En: México: Panorama histórico y cultural. I. El escenario geográfico: Introducción ecológica. Instituto Nacional de Antropología e Historia, Depaartamento de Prehistoria. pp. 19-56.

Dressler R.L. 1954. Some floristic relationships between Mexico and United States. Rhodora 56:81-96.

Florin R. 1963. The distribution of conifer and taxad genera in time and space. Acta Horti Bergiani. Band 20:312.

Graham, A. 1964. Origin and evolution of the biota of southeastern North America: Evidence from the fossil plant record. Evolution 18:571-585.

Graham. A 1969. Studies in Neotropical paleobotany. I The Oligocene communities of Puerto Rico. Annals of the Missouri Botanical Garden 56:308-357.

Graham. A. 1977. The tropical rain forest near its northern limits in Veracruz, Mexico. Recent and ephemeral? Boletín de la Sociedad Botánica de México 36:13-20.

Graham. A. 1989. Late tertiary paleoaltitudes and vegetational sonation in Mexico and Central America: Acta Botánica Neerl 38:417-424.

Graham A. 1993. Historical factors and biological diversity in México. En: Ramamoorthy T.P., Bye R., Lot A. y Fa J. Biological diversity of Mexico. Origins and distribution. Oxford University Press. New York. 818 p.

Guzmán E.J. y Zoltan De Cerna. 1963. Tectonic history of Mexico. American Association of Petrol. Geol. Mem. 2:113-129.

Hollick A. 1906. The Cretaceous flora of southern New York and New England. U.S. Geol. Surv. Monogr. 50:1-219.

Komarek E.V. 1983. Fire as an anthropogenic factor in vegetation ecology. En: Man's impact on vegetation. Holzner W., Werger M.J.A. and Ikusima II. Eds. Dr. W. Junk Publishers. The Hague, Boston-London. 77-82 p.

Martin P.S. and Harrell B F. 1957. The Pleistocene history of temperate biotas in Mexico and eastern United States. Ecology 38:468-480.

Manchester S.R. 1983. Eocene fruits, wood and leaves of the Fagaceae from the Clarno Formation of Oregon. American Journal of Botany 70:74 (Abstract).

Medellín L.F. 1982. The Chihuahuan Desert. En: Bender Gordon (Ed.) Reference handbook on the deserts of North America. 6. 321-381. West part. Greenwood press.

Miller C.N. Jr. 1977. Mesozoic conifers. Botanical Review 43:217-280.

Miranda F. and Sharp A.J. 1950. Characteristics of the vegetation in certain temperate regions of eastern Mexico. Ecology 31:313-333. 
Mirov N.T. 1967. The genus Pinus. New York: The Ronald Press.

Nixon K.C. 1993. The genus Quercus in Mexico. In: Ramamorthy T.P., Bye R., Lot A. and Fa J. Eds. Biological Diversity of Mexico. Origins and distribution. Oxford University Press. New York. p. 447-458.

Powell M.A. and Turner B.L. 1977. Aspects of the plant gypsum outcrops of the Chihuahuan Desert. En: Wauer R.H. and Riskimd D.H. Eds. Transactions of the Symposium on the Biological Resources of the Chihuahuan Desert Region. U. S. and Mexico. Transctions and Proceeding Series 3:315-325. Washington, D.C.: National Park Service.

Raven P.H. and Axelrod D. 1974. Angiosperm biogeography and past continental movements. Annals of the Missouri Botanical Garden 61:539-673.

Rueda-Gaxiola J. 1967. Contribution à l'etude palynologique et pétrographique du charbon cretacé du Bassin de Sabinas, Coahuila, Mexique. Tesis. Faculté des Sciences. Université de Lille. 3 vols.

Rzedowski J. 1962. Contribuciones a la fitogeografía florística e histórica de México. I. Algunas consideraciones acerca del elemento endémico en la flora mexicana. Boletín de la Sociedad Botánica de México 27:52-65

Rzedowski J. 1975. An ecological and phytogeographical analysis of the grassland of México. Taxon 24:67-80.

Rzedowski J. 1991. Diversidad y orígenes de la flora fanerogámica de México. Acta Botánica Mexicana 14:3-21.

Sharp A.J. 1951. The relation of the Eocene Wilcox Flora to some modern floras. Evolution 5:1-5.
Sharp A.J. 1966. Some aspects of mexican phytogeography. Ciencia 24:229-232.

Steeves M.W. 1959. The pollen and spores of the Raritan and Magothy formations (Cretaceous) of Long Island. Unpubl. Ph.D. Thesis, Radcliffe College, Cambridge. 237 p.

Styles B.T. 1993. Genus Pinus: A mexican preview. En: Ramamorthy T.P., Bye R., Lot A. and Fa J. Eds. Biological diversity of Mexico. Origins and distribution. Oxford University Press. New York. 397-420 pp.

Toledo V.M. 1969. Diversidad de especies en las selvas altas de la planicie costera del Golfo de México. Tesis Facultad de Ciencias. Universidad Nacionaal Autónoma de México. México D. F. 55 pp.

Toledo V.M. 1976. Los cambios climáticos del Pleistoceno y sus efectos sobre la vegetación tropical cálida y húmeda de México. Tesis Maestría en Ciencias. Facultad de Ciencias Universidad Nacionaal Autónoma de México. México 73 p.

Wells P.V. 1977. Post-glacial origin of the present Chihuahuan Desert less than 11,500 years ago. En: Wauer and R.H. and Riskind D.H. Eds. Transactions of the Symposium on the biological resources of the Chihuahuan desert region, U.S. and Mexico. Transactions and Proceeding Series 3:67-83. Washington, D. C. National Park Service.

Wendt T. 1993. Composition, floristic affinities, and origins of the canopy tree flora of the Mexican Atlantic slope rain forest. En: Ramamorthy T.P., Bye R., Lot A. and Fa J. Eds. Biological diversity of Mexico. Origins and distribution. Oxford University Press. New York 1993. 812 pp. 